\title{
O LEGADO TEÓRICO POLÍTICO DE MARX NO BICENTENÁRIO DE SEU NASCIMENTO
}

\author{
Marx's theoretical political legacy in the bicentennial of his birth / El legado teorico \\ politico de Marx en el Bicentenario de su nacimiento
}

Gonzalo Adrián Rojas ${ }^{1}$ y Shimenny Ludmilla Araujo Wanderley ${ }^{2}$

\begin{abstract}
RESUMO
O bicentenário do nascimento de Karl Marx é um convite a revisitar seu legado teórico e político, parafraseando Lenin, nasTrês fontes e as três partes integrantes do marxismo, escrito na ocasião dos 30 anos da sua morte, em 1913, uma vez que ainda suscita a hostilidade e o ódio do conjunto das classes dominantes, assim como quando não a sua negação, a sua simplificação na academia, o que não deixa de ser lógico numa sociedade que tem como base a luta de classes, onde não pode existir uma ciência "imparcial". A partir da análise crítica da filosofía alemã, o socialismo francês e a economia política inglesa conseguem realizar uma superação dialética, articulando a economia, política, filosofia e a história, entendidas como separações analíticas de uma realidade que faz parte de um todo social. O objectivo desta comunicação é apresentar um conjunto de categorias teóricas que vão aparecendo em algumas das suas principais obras e que sempre tem relação com uma táctica de intervenção na luta de classes do proletariado, no marco de uma estratégia revolucionária. É uma abordagem muito geral, sendo que cada livro de Marx merecería uma análise específica, neste artigo limitamo-nos em termos de teoria e filosofia política, desse modo, não abordaremos acerca das suas contribuições na crítica da economia política burguesa. Concluímos com a necessidade da luta teórica e política pela independência da classe trabalhadora e de recuperar comunismo como projecto político, revolucionário há 200 anos do nascimento de Marx.
\end{abstract}

Palavras-chave: Karl Marx, Materialismo Histórico,Luta de Classes, socialismo Científico, Comunismo

Recebido: Junho $2018 \quad$ Aceitado: Julho 2018

\footnotetext{
${ }^{1}$ Professor Dr. Ciência Política, Unidade Acadêmica de Ciências Sociais (UACS), Programa do Pós-graduação em Ciência Política (PPGCP) e no Programa de Pós-graduação em Ciências Sociais (PPGCS) da Universidade Federal de Campina Grande (UFCG), Campina Grande, Paraíba. E-mail: gonzalorojas1969@hotmail.com

${ }^{2}$ Mestranda no Programa de Pós-graduação em Ciências Sociais da Universidade Federal de Campina Grande (PPGCS/UFCG). E-mail: shimennyaraujo@yahoo.com.br
} 


\title{
RESUMEN
}

El bicentenario del nacimiento de Karl Marx es una invitación a revisar su legado teórico y político, parafraseando a Lenin de las tres fuentes y partes integrantes del Marxismo; escrito en la ocasión de los 30 años de su muerte en 1913, resaltando la hostilidad y odio del conjunto de las clases dominantes, sin negar su simplificación en la academia, lo que eslógico en una sociedad basada la lucha de clases, donde no puede existir una ciencia "imparcial". A partir del análisis crítico de la filosofía alemana, el socialismo francés e la economía política inglesa, se consigue realizar una discusión dialéctica articulando economía, política, filosofía e historia, entendidas como separaciones analíticas de una realidad que hace parte de un todo social. El objetivo de este documento es presentar un conjunto de categorías teóricas que van apareciendo en algunas de sus principales obras y que siempre tiene relación con una táctica de intervención en la lucha de clases del proletariado, en el marco de la estrategia revolucionaria. Es un abordaje muy general, puesto que cada libro de Marx merecería una nalisis especifico, en esta documento se realiza un recorte en términos de teoría y filosofía política, de este modo, no se abordaran sus contribuciones en la critica de la economía política burgues. Se concluye con la necesidad de lucha teorica y política por la independencia de la clase trabajadora y de recuperar el comunismo como proyecto político revolucionario a 200 años del nacimiento de Marx.

Palabras clave: Karl Marx, materialismo histórico,lucha de clases, socialismo científico, comunismo.

\begin{abstract}
The bicentenary of the birth of Karl Marx is an invitation to revisit his theoretical and political legacy, paraphrasing Lenin in the Three Sources and the three integral parts of Marxism, written on the occasion of the 30th anniversary of his death in 1913, still raises hostility and hatred of the whole of the ruling classes, as well as when not its negation, its simplification in the academy, which is still logical in a society based on class struggle, where there can be no "impartial" science. From the critical analysis of German philosophy, French socialism and English political economy, it achieves a dialectical overcoming by articulating economics, politics, philosophy and history, understood as analytical separations of a reality that is part of a social whole. The purpose of this communication is to present a set of theoretical categories that are appearing in some of his main works and which are always related to a tactic of intervention in the class struggle of the proletariat, within the framework of a revolutionary strategy. It is a very general approach, since each book of Marx deserves a specific analysis, in which we make a cut in terms of political theory and philosophy, so we will not address its contributions in the critique of bourgeois political economy. We conclude with the necessity of the theoretical and political struggle for the independence of the working class and to recover communism as a revolutionary political project 200 years after the birth of Marx.
\end{abstract}


O legado teórico político de Marx no bicentenário de seu nascimento.

Keywords: Karl Marx, historical materialism, class struggle, scientific socialism, communism.

\section{INTRODUÇÃO}

O bicentenário do nascimento de Karl Marx é um convite a revisitar seu legado teórico e político. Parafraseando a Vladimir llitch Lenin nas Três fontes e as três partes integrantes do marxismo(Lenin, 2001), escrito na ocasião dos 30 anos de sua morte em 1913, ainda suscita a hostilidade e o ódio do conjunto das classes dominantes, assim como quando não sua negação, sua simplificação na academia, o que não deixa de ser lógico numa sociedade que tem como base a luta de classes, onde não pode existir uma ciência "imparcial".

A partir da análise crítica da filosofia alemã, do socialismo francês e da economia política inglesa, o filósofo de Tréveris, consegue realizar uma superação dialética articulando economia, política, filosofia e história, entendidas como separações analíticas de uma realidade que faz parte de um todo social.

O objetivo deste artigo é apresentar um conjunto de categorias teóricas que vão aparecendo em algumas de suas principais obras e que sempre tem relação com uma tática de intervenção na luta de classes do proletariado no marco de uma estratégia revolucionária. É uma abordagem muito geral, posto que cada livro de Marx mereceria uma análise específica, nesta realizamos um recorte em termos de teoria e filosofia política, desse modo, não abordaremos suas contribuições na crítica da economia política burguesa.

\section{A CRÍTICA DA FILOSOFIA ALEMÃ}

Entre dezembro de 1843 e 1845, Karl Marx escreve um conjunto de textos que tem relação com saldar as contas com a filosofia alemã, mas que tem uma clara importância política e econômica. Estes textos são a Introdução a Crítica da Filosofia do Direito de Hegel (Marx, 2005), Para questão judaica (Marx, 2009), os Manuscritos econômico-filosóficos (Marx, 2010), A ideologia alemã (Marx, 2007a) e as Teses sobre Feuerbach (Marx, 2007a).

$\mathrm{Na}$ Introdução a Crítica da Filosofia do Direito de Hegel, escrito entre dezembro 1843 e janeiro 1844, destacamos a relação entre: a) a crítica religiosa e 
a crítica da política; b) a crítica irreligiosa, a crítica do Estado e c) é uma de suas primeiras menções ao proletariado como sujeito político da Revolução.

Marx mostra a necessidade de ir além da crítica à religião, já realizada pela burguesia na sua luta contra a ordem cristão-feudal, que em termos filosóficos tem seu ponto mais alto no materialismo de Ludwig Feuerbach no seu livro $A$ essência do cristianismo (Feuerbach, 1988), e afirma que é preciso avançar na crítica ao Estado diferenciando analiticamente entre Estado e Estado cristão, um Estado burguês "puro", como seria o francês, do Estado Cristão, o alemão, que reproduz as relações sociais burguesas mas que não é independente da religião.

Aqui Marx apresenta uma frase muito conhecida de seu legado, mas poucas vezes apresentada na sua totalidade:

"A miséria religiosa constitui ao mesmo tempo a expressão da miséria real e o protesto contra a miséria real. A religião é o suspiro da criatura oprimida, o ânimo de um mundo sem coração, a alma das situações sem alma, a religião é ópio dos povos" (Marx, 2005; p. 145)

É preciso abolir a religião como felicidade ilusória para lutar pela felicidade real.A burguesia revolucionária francesa crítica a religião, mas não faz a crítica da política nem de seu Estado. Marx afirma pontos centrais como que o homem é um ser social e que são o Estado e a sociedade os que produzem a religião e não que a religião faz aos homens.

O objetivo de Marx é transformar a crítica do céu em crítica da terra, a crítica da religião em crítica do Estado e a crítica da teologia em crítica da política. Mas esta crítica da filosofia do direito não é uma crítica interna, só filosófica, mas que só se propõe tarefas que podem ser resolvidas pela atividade prática, a praxis. Isto podemos vincular com a Teses sobre Feuerbach (Marx, 2010), escritas em 1845, onde depois de criticar tanto o idealismo, que entende que é a atividade intelectual que cria a realidade como o materialismo empirista mecanicista que narra os fatos como eles se apresentam de modo imediato, diferenciando este do materialismo histórico dialético. Na Teses XI sobre Feuerbach, Marx apresenta a filosofia da práxis quando expõe que até esse momento histórico os filósofos têm apenas interpretado o mundo de maneiras diferentes; mas que a questão, porém, 
O legado teórico político de Marx no bicentenário de seu nascimento.

é transformá-lo (Marx, 2010), uma tarefa que está por fora da própria filosofia. Bem como afirma na Ideologia Alemã, também escrita em 1845, as ideias de uma época são as ideias da classe dominante, é justamente uma práxis revolucionária o que muda as consciências e transforma a realidade, a pratica como prova da verdade.

Continuando com a crítica a George Hegel, o maior filósofo da burguesia enquanto esta era ainda uma classe revolucionária, o teórico do Estado Ético, que entendia que o homem só poderia ser livre no Estado, Marx entende que esse Estado é de classe e a esfera da alienação, por isso as possibilidades de emancipação do proletariado está na formação de uma classe que tenha cadeias radicais, de uma classe da sociedade civil que não seja uma classe da sociedade civil, de um estamento que seja a dissolução de todos os estamentos, de uma esfera universal porque seus sofrimentos são universais, de uma esfera que não possa se emancipar sem emancipar ao conjunto da humanidade, que só pode se redimir redimindo totalmente ao homem. A dissolução como classe particular é o proletariado moderno, sendo aqui onde aparece o proletariado como sujeito histórico, o que diferenciará claramente o socialismo científico, o comunismo, das diferentes e heterogêneas versões socialistas utópicas. O "descobrimento" do proletariado como classe universal, significa um avanço gigantesco que desenvolverá junto com Friedrich Engels no Manifesto do Partido Comunista (Marx-Engels, 2007), escrito em dezembro de 1847. Pela sua vez, o conceito de alienação será trabalhado nos Manuscritos Econômico-Filosóficos (Marx, 2010), escrito em 1844, também por Marx, mais ainda sem o conceito de exploração. Sobre isto entendemos que é preciso diferenciar os conceitos de alienação e exploração como realizará Marx, e não os opor.

Por fim, no livro A questão judaica (Marx, 2009), também escrito em 1844, é relevante na sua polêmica com Bruno Bauer, realizando uma diferenciação entre o conceito emancipação política, defendido por Bauer, um ex-professor da cátedra de Teologia na Universidade de Bonn expulso acusado de ateísmo, com o conceito de emancipação humana. Bauer entendia que era preciso que o Estado Cristão alemão, um estado religioso, outorgue os mesmos direitos aos judeus, 
direitos políticos. Marx expõe os limites da emancipação política mesmo constitucional na França, porque emancipação política numa sociedade dividida em classes continua sendo a expressão da desigualdade social, por isso defende a necessidade da luta é pela emancipação humana no marco de uma luta anticapitalista sem exploração.

\section{O MANIFESTO DO PARTIDO COMUNISTA: A IMPORTÂNCIA DA LUTA PELA INDEPENDÊNCIA POLÍTICA DA CLASSE TRABALHADORA}

Em 1947, a Liga dos Comunistas solicita a Marx e Engels a elaboração de um programa do partido, tanto teórico como político prático, para explicitar os conteúdos do comunismo pela própria voz dos comunistas, que já tinham que ser reconhecido pelos seus detratores como uma força política real na Europa. O Manifesto do Partido Comunista (Marx-Engels, 2007) será publicado em 1848 e terá como objetivo guiar o proletariado na luta de classes que entre 1848-1850 se realiza na França e na Europa, e que é conhecida, segundo o historiador marxista Eric Hobsbawm, como a "primavera dos povos" (Hobsbawm, 2010)

O central é que o programa apresenta pela primeira vez a necessidade da independência política da classe trabalhadora. Até 1848 os proletários lutavam junto a burguesia contra os elementos da ordem cristão feudal ainda existentes na Europa, a partir de 1848 os trabalhadores deixam de lutar contra os inimigos de seus inimigos para lutar contra seus verdadeiros inimigos: a burguesia.

O manifesto tem quatro partes.

A primeira é "burgueses e proletários" onde define claramente estes, a burguesia, como os proprietários dos meios de produção, e os proletários como aqueles que não tem propriedade alguma, são duplamente livres, livres juridicamente e livres de seus meios de produção e da terra, para serem explorados no mercado mundial capitalista, como Marx desenvolverá melhor no Capítulo XXIV de O Capital (Marx, 2013) quando fala do processo da acumulação primitiva de capital. O importante é como analisam o processo histórico de construção da burguesia, o do proletariado e apresentam os conceitos de classe, fração de classe, luta de classes e Estado. 
O legado teórico político de Marx no bicentenário de seu nascimento.

Toma como ponto de partida que a história da humanidade não é outra coisa que a história da luta de classes, que não se produz em toda sociedade senão naquelas em que os interesses entre as classes são irreconciliáveis. Amosescravos no modo de produção da escravidão, senhores feudais-servos no feudalismo e burgueses e proletários na moderna sociedade capitalista. Surge o Estado como uma instituição para garantir a dominação de classe. O Estado será definido no capitalismo como um comitê que administra os negócios comuns da burguesia, que deve garantir a reprodução da sociedade burguesa, que a propriedade privada seja legal, o mesmo que a exploração da força de trabalho, para garantir a acumulação rentável de capital num território.

É muito relevante como Marx e Engels apresentam a relação entre burguesia e proletariado e que a burguesia na medida que se desenvolve leva com ela a seu próprio coveiro: o proletariado como sujeito histórico revolucionário.

$\mathrm{Na}$ segunda parte do Manifesto apresenta a particularidade dos comunistas a importância do programa e sua relação com os proletários, em quanto que na terceira parte faz um "debate de tendências" com as diferentes variantes de socialismo utópico, incluindo aos anarquistas, reivindicando frente a estes a luta política pelo poder político do Estado. Aqui o socialismo científico é sinônimo de comunismo e se diferencia claramente das diferentes variantes socialistas utópicas que realizam críticas a sociedade burguesa, as vezes até apresentam elementos de uma sociedade melhor, mas não apresentam como será possível passar desta sociedade a sociedade pretendida. O proletariado como sujeito político histórico é uma diferença central do socialismo científico do utópico como já foi mencionado, como ator social que produto das contradições da própria sociedade burguesa, construirá a sociedade comunista.

$\mathrm{Na}$ quarta parte do Manifesto, são apresentadas as relações dos comunistas com os diferentes partidos de oposição em vários países, sendo sua conclusão internacionalista, posto que se o capitalismo é um modo de produção mundial, só pode ser superado de forma revolucionária no marco internacional e finaliza exortando a necessidade de unidade da classe trabalhadora de todos os países na famosa frase: "Proletários de todos os países uni-vos !!!". 
As lutas de classes na França (Marx, 2012a), por sua vez, será como afirmará Engels na sua famosa Introdução de 1895 nesse mesmo livro (Engels, 2012 in Marx, 2012a), o primeiro texto em que Marx utilizará o método materialista histórico para o estudo de uma parte da história, de um processo político. Isto por si mesmo fala da importância da obra, mas também realiza uma autocrítica sobre algumas hipóteses que trabalhavam com Engels no Manifesto do Partido Comunista (Marx-Engels, 2007), depois da derrota das revoluções na França e na Europa. Tira como uma conclusão que desenvolverá no Prefacio de Para a crítica da Economia Política (Marx, 2000) escrita em 1859, que nenhuma sociedade desaparece sem haver desenvolvido a totalidade de suas forças produtivas e que os homens não se põem tarefas que não conseguem realizar. Leon Trotsky, quando escreve na ocasião dos 90 anos do Manifesto, expõe que Marx e Engels confundiram as dores de parto do capitalismo com as dores de sua agonia final (Trotsky, 2007 in Marx-Engels, 2007).

\section{O XVIII BRUMÁRIO DE LUIS BONAPARTE}

Um livro central no percurso da obra de Marx, é constituído por um conjunto de artigos enviados a New York e que são publicados em 1852 com o título do XVIII Brumario de Luis Bonaparte (Marx, 2011). Marx, realiza uma excelente análise da conjuntura e do processo político que acabou no golpe de Luís Bonaparte. Destacamos principalmente a relação entre interesses materiais e conflitos, a existência de classes e frações de classe e que existe uma separação entre economia e política, que os partidos políticos representam os interesses das classes e suas frações. Também a importância do Parlamento para a burguesia, apresentado como mais que o campo neutro onde as diferentes frações da burguesia, a grande propriedade territorial, latifúndio, indústria e capital financeiro podem conviver "civilizadamente" com igualdade de direitos, mas onde podem esses interesses unificar-se e serem apresentados como os do conjunto da sociedade. Também são muito relevantes os conceitos de Bonapartismo e de crise política. 
O legado teórico político de Marx no bicentenário de seu nascimento.

No prólogo da segunda edição do XVIII Brumário de Luis Bonaparte (MarX, 2011), publicado em Hamburgo em 1869, o próprio Marx faz duas observações.

A primeira é que escreveu todos os textos que compõem o livro, a pedido de Joseph Weydmeyer, jornalista e comandante militar do distrito de Saint Louis (Missouri) no exército da União durante a Guerra Civil nos Estados Unidos e que os materiais trabalhados não passam o ano de 1852. Nesse sentido, é uma análise de conjuntura materialista histórico, em termos leninistas, uma análise concreta de uma situação concreta no contexto de uma formação econômica e social.

A segunda observação é uma diferenciação com obras como a de Victor Hugo, Napoleão le petit (o pequeno), mas que contraditoriamente com o título conclui que é tudo um ato de força um indivíduo ou como a do anarquista Joseph Pierre Prudhomme, que ao reivindicar que o Golpe de Estado é o produto de um processo anterior, aparece como uma apologia do golpe de estado.

A hipótese central de Marx é que a luta de classes criou na França as condições que permitiram a um personagem medíocre e grotesco desempenhar 0 papel de herói.

Marx também diferencia conceitualmente o bonapartismo, uma categoria política da sociedade burguesa moderna, do conceito de cesarismo, uma categoria política que se refere a Roma antiga sob o modo de produção escravista, alegando que só pode ser usado como uma analogia histórica superficial, uma figura política para comparar alguns elementos, mas não como uma categoria histórica.

O livro de Marx, que tem sete partes, no primeiro já apresentava, além de uma periodização, que concluiria também a parte seis de maneira mais resumida, a distinção teórica entre revoluções burguesas e proletárias, a tensão entre estruturas e sujeitos: os homens e as mulheres fazem a história, primazia dos sujeitos, mas em condições que eles não escolhem, limitados pela estrutura. Marx apresenta a mencionada tensão, que é o mais importante (Marx, 2011)

Analisaremos especificamente, nesta parte deste artigo, a parte seis deste livro, destacando um conjunto de categorias históricas, sua relação e sua 
importância para a análise da conjuntura. Essa parte apresenta a relação entre interesses materiais e conflitos, classes e frações de classe, partidos políticos e sua mediação a traves da representação de interesses a nível político, a importância do Parlamento para a burguesia, a crise política e sua opção para o golpe de Luis Bonaparte como elementos centrais de um todo numa análise conjuntural.

Levando em consideração essa tensão na sexta parte, apresentam-se os atores políticos vinculados ao processo político estudado, a partir de uma análise das classes e das frações de classe que eles expressam. A burguesia como classe, como um todo defende a propriedade privada e é contra o proletariado, sempre, mas também a classe dominante tem frações de classe, estas frações têm interesses específicos e permanentes, são frações de uma mesma classe, por isto para Marx os trabalhadores devem manter sua independência política contra qualquer uma dessas frações.

O Partido da Ordem é formado pelos legitimistas (latifundiários) e os orleanistas (aristocracia financeira e capital industrial), além da alta burguesia. Estavam fortemente representados nos Conselhos dos Departamentos no conflito entre Luis Bonaparte e o Parlamento, eles são a favor das reformas propostas e são maioria no Parlamento. Ao aprofundar-se a crise política, é dividida nas frações originais e, por sua vez, estas são divididas novamente.

Os republicanos puros são burgueses de ideias republicanas, lutavam contra a aristocracia financeira e eram contra o proletariado e as ideias socialistas, de modo que serviam à fração da burguesia industrial.

Os socialdemocratas são o partido que publica o jornal La Montaña, com base na população rural, a grande maioria dos deputados de Paris e com certa presença no exército. Marx observa que eles se comportam pedindo armas no Parlamento, mas de forma parlamentar nas ruas. As ameaças revolucionárias da pequena burguesia e seus representantes democráticos nada mais são que tentativas de intimidar o adversário como sinal de sua impotência política. Importante entender aqui socialdemocratas como categoria histórica, uma coisa é o socialdemocrata na época de Luis Bonaparte, e outra é antes da Primeira 
O legado teórico político de Marx no bicentenário de seu nascimento.

Guerra Mundial, lembrar que tanto Karl Kautsky, liderança da corrente reformista, como Vladimir I. Lenin, na corrente revolucionária, eram socialdemocratas, assim como também temos que diferenciar a estes da socialdemocracia após a Segunda Guerra Mundial.

Os bonapartistas são os apoiadores do sobrinho do tio. Formam a base de Luis Bonaparte a Sociedade de 10 de dezembro, uma sociedade beneficente aparente, mas organizando ao lumpemproletariado em seções secretas, sendo dirigidos por agentes bonapartistas e tendo na cabeça um Geral bonapartista. Luis Bonaparte, por sua vez, é o sobrinho do tio e representa tanto o lumpenproletariado como o camponês conservador, se apresentando como a unidade da nação, como se estivesse acima das classes, mas defende um interesse de classe, que é o da burguesia em geral, do governo e do Estado.

Aqui é importante fazer uma observação epistemológica, a separação entre economia, política e sociedade são separações analíticas, na realidade, para Marx o todo social é parte de uma mesma totalidade.

É importante observar a complexa relação entre interesses materiais e conflitos, bem como as classes e as frações de classe em seu relacionamento com os representantes políticos desses interesses que não acontecem automaticamente, senão não se consegue entender a crise política.

Porque se a república parlamentar é tão importante para a burguesia, acaba defendendo o golpe de Luis Bonaparte

A república parlamentar significa muito mais para a burguesia que o campo neutro onde suas diferentes frações poderiam conviver com igualdade de direitos. O papel do Parlamento foi central na construção de seu domínio comum, era uma forma de governo na qual eles poderiam defender seu interesse geral de classe, sendo a fração hegemônica que permitiria que outras frações expressassem sua política, poderia também apresentar os seus interesses em conjunto com as outras classes da sociedade.

A política é a arena em que a burguesia pode "unificar" os seus interesses de classe e impor o seu domínio às outras classes da sociedade. A república parlamentar serviu como uma fusão. 
O problema político surge com conflitos no Parlamento sobre a reforma constitucional, centralmente sobre a possibilidade de reeleição de Luis Bonaparte, sendo um conflito que expressava a inviabilidade do partido da ordem. A possibilidade de fusão monárquica não só não permite isso, mas também os divide no Parlamento.

A situação é a seguinte, é apresentada a reforma constitucional que Luis Bonaparte pretendia, porque significava a continuidade do mandato presidencial, para ser aprovada a reforma constitucional era necessários dois terços dos votos. O Parlamento, por maioria, pronuncia-se a favor de Luis Bonaparte, mas quando não chega à maioria que precisa da Constituição, pronuncia-se contra o Parlamento.

A crise política é tão profunda que o partido da ordem no Parlamento apresenta um conflito entre a burguesia extraparlamentar com representantes da burguesia no parlamento, a imprensa burguesa em conflito com a burguesia, legalistas da província com seus parlamentares, burguesia comercial com seus políticos, representantes e representados. A aristocracia financeira apoia Luis Bonaparte e a burguesia industrial não aceita mais o conflito entre ela e o Parlamento, porque gerou instabilidade política.

Aqui a tese de Marx é reforçada, o golpe de Estado de Luis Bonaparte é feito com a dissolução da Assembleia Nacional, sendo o golpe o resultado de eventos anteriores, em um contexto em que os parlamentares se tornaram um corpo de representantes "livremente" eleitos pela sua aldeia em usurpadores de uma classe.

O partido da burguesia em geral entendia que a crise política constituía uma perturbação para seus negócios privados, sendo Luis Bonaparte o único capaz de garantir a ordem. A massa extraparlamentar da burguesia estava pronta para libertar-se de seu próprio domínio, a fim de libertar-se dos perigos daquele domínio, a instabilidade política. Em sua leitura, foram os conflitos políticos que geraram a crise econômica.

A ordem é central para a burguesia em um modo de produção como 0 capitalismo, a estabilidade é central, pois é um sistema no qual deve ser investido 
hoje para ter lucro amanhã, de modo que a estabilidade e a ordem política reatam a relação entre o presente e o futuro,uma relação central para a acumulação capitalista. É por isso que a burguesia prefere, como afirmar Marx, um fim do terror, o golpe de Luis Bonaparte ao fechar o Parlamento, que um terror sem fim, que era a permanente instabilidade política.

A massa extraparlamentar da burguesia reafirma no processo sua ruptura com a burguesia no Parlamento, a burguesia industrial também apoia a aniquilação do Parlamento, a queda de seu próprio domínio e a ditadura de Luis Bonaparte que dissolve a Assembleia Nacional e o Conselho de Estado, colocando sob estado de sítio o departamento de Siena, enquanto restaura o sufrágio universal.

Em tempos de uma crise orgânica do capitalismo mundial, que se aprofunda desde 2008, e se expressa com força crescente nas formações econômico-sociais na América Latina, com governos que cada vez mais aprofundam seus elementos bonapartistas e autoritários, e que recebem de forma desigual como resposta a luta de classes e muito relevante incorporar conceitos e lições do XVIII Brumário (Marx, 2012a).

\section{A COMUNA DE PARIS}

$\mathrm{Na}$ Mensagem da Associação Internacional dos Trabalhadores, a I Internacional, no texto que é conhecido como a Guerra Civil na França (Marx, 2007b), de 1871, Marx analisa também a Comuna de Paris, no marco da guerra franco-prussiana, a primeira experiência de tomada do poder político pelo proletariado, tanto conceitualmente opondo formas de estado que remetem à regimes sociais diferentes como o Império e a Comuna, sendo a Comuna a antítese do Império, assim como suas propostas políticas que podem ser consideradas transicionais.

Entre as propostas políticas destacamos como exemplo que todo político receba o mesmo salário que um operário qualificado, e que os juízes sejam eleitos e revogáveis, tais medidas visavam abolir toda casta privilegiada; pretendia-se a 
redução da jornada de trabalho, bem como a auto-gestão operária nas fábricas, entre outras.

Marx desenvolveu a teoria de que, se todo Estado é produto da divisão em classes da sociedade, se tem classes, tem estado, uma forma de organização política.

A partir da Comuna de Paris, identificará a ditadura do proletariado com a forma política da Comuna. Importante lição da Comuna apresentada por Engels, é que não é possível usar o Estado burguês e colocá-lo a funcionar em benefício da classe trabalhadora. Marx defende a destruição do Estado burguês e sua substituição por uma nova forma de organização política, posto que depois de uma revolução não desaparecem automaticamente as classes.

Dito isto, é primordial diferenciarmos aparelho de Estado de suas formas políticas, o aparelho de Estado depende do regime social, mas pode ter uma variedade de formas políticas. Nos referimos ao sentido dado por Lenin no final do capítulo II do Estado e a Revolução (Lenin, 2017), a transição do capitalismo para o comunismo, está claro, não pode deixar de dar enorme profusão e variedade de formas políticas, mas sua essência será inevitavelmente uma só: a ditadura do proletariado.

Esse período de transição, que na Crítica ao Programa de Gotha (Marx, 2012b), escrito por Marx entre abril e maio de 1875 e onde polemiza com as ideias de Ferdinad Lasalle, é denominado como primeira fase do comunismo ou socialismo. Essa nova forma de organização estatal que tem como objetivo ir definhando na medida que desaparecem as classes, no comunismo é denominada ditadura do proletariado. Pela primeira vez na história da humanidade que a maioria domina sobre a minoria.

\section{BREVE CONCLUSÃO}

A necessidade da luta teórica e política pela independência da classe trabalhadora, dos patrões, dos governos e do Estado, se organizando em partido revolucionário para sua intervenção na luta de classes, na perspectiva da luta pelo poder político do estado, para destruir o Estado burguês, instaurar uma ditadura 
do proletariado como fase de transição necessária à sociedade sem classes, nem estado. Depois de décadas de usurpação stalinista do conceito, é preciso hoje, dois séculos do nascimento do revolucionário de Tréveris, recuperar o comunismo como projeto político revolucionário. Por tudo isto, é central retomar a Marx 200 anos após seu nascimento.

\section{REFERÊNCIAS BIBLIOGRÁFICAS}

Engels, Friedrich (2012) Introdução de 1895. MARX, Karl. As lutas de classes na França (primeira edição).Boitempo, Brasil.

Feuerbach, Ludwig (1988) A essência do cristianismo (primeira edição). Papirus. Brasil.

Hobsbawm, Eric (2010) A era do capital - 1848-1875 -. (decimo quinta edição). Paz e Terra. Brasil.

Lenin, Vladimir llitch (2001) As três fontes e as três partes integrantes do marxismo (primeira edição). Expressão Popular. Brasil.

Lenin, Vladimir llitch (2017) O Estado e a Revolução (primeira edição). Boitempo: Brasil.

Marx, Karl (2000) Para a Crítica da Economia Política (primeira edição). Nova Cultural: Brasil.

Marx, Karl (2005) Introdução de 1843. Marx, Karl. Critica da Filosofia do direito de Hegel (primeira edição).Boitempo. Brasil.

Marx, Karl (2007a) Marx sobre Feuerbach (com alterações de Engelsde 1888). Karl, Marx. A ideologia alemã(primeira edição). Boitempo. Brasil.

Marx, Karl (2007b) A guerra civil na França (primeira edição). Boitempo. Brasil.

Marx, Karl (2009) Para a questão judaica (primeira edição). ExpressãoPopular. Brasil.

Marx, Karl (2010) Manuscritos económico-filosóficos (primeira edição). Boitempo. Brasil.

Marx, Karl (2011) O 18 Brumário de Luis Bonaparte (primeira edição). Boitempo. Brasil.

Marx, Karl (2012a) As lutas de classes na França (primeira edição). Boitempo. Brasil

Marx, Karl (2012b) Crítica ao Programa de Gotha (primeira edição).Boitempo. Brasil

Marx, Karl (2013) O Capital. Livro I (primeira edição).Boitempo. Brasil

Marx, Karl e Engels, Friedrich (2007) Manifesto do Partido Comunista. (quinta edição).Boitempo. Brasil. 